\title{
Press-On Composite Container Closure
}

National Cancer Institute

\section{Source}

National Cancer Institute. Press-On Composite Container Closure. NCI Thesaurus. Code C96124.

A metal/plastic composite cap composed of a plastisol lined metal disk, assembled to a plastic band. The closure requires a simple glass bead finish common on bowls, tumblers and carafes. 